The Sustainable City XII 135

\title{
THE RELATIONSHIP BETWEEN CONSERVATION- REVITALIZATION PROJECTS AND SITE MANAGEMENT PLAN: A CASE STUDY FOR SÜLEYMANIYE MOSQUE AND ITS ENVIRONS
}

\author{
KORAY ÖZCAN \& ŞAZIYE BAL \\ Department of Urban and Regional Planning, Pamukkale University, Turkey
}

\begin{abstract}
The aim of this paper is to examine the relationship between site management plans and the conservation-revitalization projects in context of the spatial-functional plan decisions and institutional authority-responsibility. These examinations have been handled with a method which depends on comparative-assessment of three basic data sources: conservation plans, conservation-revitalization projects and site management plan. The case study is The Süleymaniye Mosque and its environs which had been declared "historic-urban protected site" in 1977 and was inscribed on UNESCO World Heritage List within the scope of "Historic Areas of Istanbul" in 1985.However; socio-spatial and functional strategies for the Süleymaniye Mosque and its environs have been determined by Historical Peninsula Site Management Plan dated 2009. We believe that this study will present alternative perspectives to the problems arising in the context of coordination among stakeholders in the process of conservation-revitalization of historical urban environments through the re-evaluation of the institutional and managerial scope and content of the site management models through the case of Turkey.

Key words: conservation-revitalization projects, site management plan, the Suleymaniye Mosque.
\end{abstract}

\section{INTRODUCTION}

Historical sites and monuments, which are called cultural heritage, play an important role in reflecting the daily rituals, beliefs, education, art and architecture of the period when they were constructed. These sites are accepted as common heritage of humanity, due to their outstanding universal values. The deterioration or destruction of any part of these sites is thought to constitute impoverishment for the all nations in the world and the protection of these sites is regarded as international responsibility [1]. Therefore, the search for the conservation of the integrity and authenticity of cultural heritage sites from all kinds of destructive action that may arise due to reasons such as traditional destructions as well as social dynamism and urbanization problems and for the maintenance of their continuity between generations has been continuing since the early 20th century. The most important of these works is the "Convention Concerning the Protection of the World Cultural and Natural Heritage", signed in 1972 by UNESCO member states to develop a multidimensional, comprehensive and participatory protection understanding, to identify a common conservation language and policies in all countries of the world. The natural and cultural heritage sites which have outstanding universal value and policies to ensure effective and holistic protection of these sites on the basis of sustainability, broad participation, cooperation and transparency principles were defined in this convention. In addition, the World Heritage Committee notes that a site management plan, including the vision for the future of the site, main objectives for the protection of the site, strategies, actions and implementation techniques have been necessary since the adoption of the convention in order to guarantee the effective and integrated protection of universal natural and cultural heritage sites. In the Operational Guidelines for the Implementation of the World Heritage Convention 
dated 2008, it is stated that as "Each nominated property should have an appropriate management plan or other documented management system which must specify how the Outstanding Universal Value of a property should be preserved, preferably through participatory means. The purpose of a management system is to ensure the effective protection of the nominated property for present and future generations" [2]. Thus, it became compulsory for the sites proposed as World Heritage or previously added to the World Heritage List to have a management plan. Following the international developments in cultural and natural heritage preservation works, Turkey also became a party to the World Heritage Convention in 1983. In addition to this, in order to ensure the coordination of our legislation on conservation with international developments, the concepts of "management site" and "management plan" were added to the Law No. 2863 on the Conservation of Cultural and Natural Property in 2004. According to this law, management plans need to be prepared not only for "World Heritage Sites" but also for all cultural and natural sites that are legally under protection and these management plans that define the responsibilities of institutions-organizations and ensure coordination-cooperation among all stakeholders need to be compatible with traditional conservation plans [3].

This study aims to examine the conservation-revitalization works for the protection of The Süleymaniye Mosque and its environs, accepted as "memory space" [4], in terms of Ottoman history, culture and architecture, along with the objectives, targets and strategies in the site management plan in terms of integrated conservation principles and coordination among stakeholders. These examinations are based on the interpretation of the social-cultural, economic and institutional contexts problems of protection-implementation that cannot be solved as an example of Süleymaniye and comparison of these problems on the basis of sustainable and integrated protection principles.

We believe that this study will present alternative perspectives to the problems arising in the context of coordination among stakeholders in the process of conservation-revitalization of historical urban environments through the re-evaluation of the institutional and managerial scope and content of the site management models through the case of Turkey.

\section{METHOD DESCRIPTIONS}

The study was conducted within a method based on the evaluation of the relation between the preservation-revitalization works and the site management plan in terms of planningimplementation processes and audit-monitoring mechanisms in the context of authorityresponsibility accompanied by written and visual sources. In this context, design planning implementation works (plans-projects and reports) in all scope and scale for the protectionrevitalization of the Süleymaniye Mosque and its environs have been examined in detail.

These examinations have been discussed as two phases:

The first is to evaluate the preservation-renovation process of Süleymaniye Mosque and its environs in chronological order (Table 1).

The second is to evaluate comparatively the relation between conservation-revitalization plans and the site management plan in the context of objectives-targets and strategies and to question the duty and responsibility areas of the stakeholders expected to take an active role in the protection process in the context of planning-implementing and auditing-monitoring mechanisms.

\section{SÜLEYMANIYE MOSQUE AND ITS ASSOCIATED CONSERVATION AREA}

The Süleymaniye district is located in the Historical Peninsula in Istanbul and is named after Süleymaniye Mosque built in 1557 by Architect Sinan. [5]. The structures that characterize the district in addition to the Mosque the Süleymaniye Mosque, are caravanserai, madrasa, 
Table 1: Chronological process of conservation-revitalization-site management works.

\begin{tabular}{|l|l|}
\hline \multicolumn{2}{|c|}{ CHRONOLOGICAL TABLE OF CONSERVATION PROCESS } \\
OF THE SÜLEYMANIYE \\
\hline 2006 & The site was declared as urban revitalization area by the ministry. \\
\hline 2011 & Last conservation plan was accepted by the municipality(effective). \\
\hline 2011 & $\begin{array}{l}\text { Historical peninsula site management plan was accepted by the } \\
\text { municipality. }\end{array}$ \\
\hline
\end{tabular}

medical school, library, bath building, hospice and imperial tombs, provide supreme examples of ensembles of palaces and religious complexes of the Ottoman period. For this reason, it was developed as a residential area preferred by religious scholars, prominent administrators of the palace and rich merchants., this site was declared as a protected area by the Ministry of Culture and Tourism in 1977 and it was taken legally under protection as one of the important places where the Ottoman neighbourhood culture was experienced.

The Süleymaniye Mosque and Its Environs Protection Site was taken to the World Heritage List in 1985 by named as "Historic Areas of Istanbul" after complying with the "cultural criteria" along with three other protected sites in Istanbul following Turkey's signing the World Heritage Convention. Other selected sites except Süleymaniye Mosque and its Environs Protection Area are Archaeological Park, Zeyrek Mosque (Pantocrator Church) and its associated conservation area) and Land Walls of Istanbul [6].

In addition to the social-political events and fires that occurred since the 18th century, the fact that life in different parts of the city, such as Galata (Pera), became attractive and that the original owners of Süleymaniye left the region [7], These changes were some of the causes leading to the socio-spatial decay of the region. However, the most important point for the district was the fact that the labour force in the country emigrated from various parts of Anatolia and settled in the empty houses of Süleymaniye after the land reform and agricultural policies in the 1950s. The majority of the people living in Süleymaniye are composed of disadvantaged groups of the society such as tenants who hardly meet even their basic economic needs and have informal jobs such as paper collecting, working at a workshop, construction, porter age and manufacturing [8].

This change has led to the demolition of architectural texture over time. However, the rapid housing without aesthetic concerns that started from the 1950s led to the increase of concrete apartment buildings in the area. The fact that these spatial destruction are brought to the agenda of the public and, on the other hand, the fact that UNESCO frequently warns of excluding the site from the list on the grounds that it is not protected required urgent intervention to the Süleymaniye cultural heritage. Therefore, the site was declared a Revitalization Site by the Ministry of Culture and Tourism in 2006 in accordance with Law No. 5366 [9].

Despite the fact that the Süleymaniye Mosque and its environs were taken under protection in 1977 and defined as a historic-urban protection area in 1995, area was not taken into consideration both because of the legal objections made to the plan decisions and because of the lack of protection awareness; so, it tooks about fifteen years for this area to be subject to comprehensive conservation work. As the last conservation plan, the Istanbul Metropolitan Municipality prepared the Historic Peninsula Site 1/ 5.000 Scale Conservation Master Plan in 2011 . 


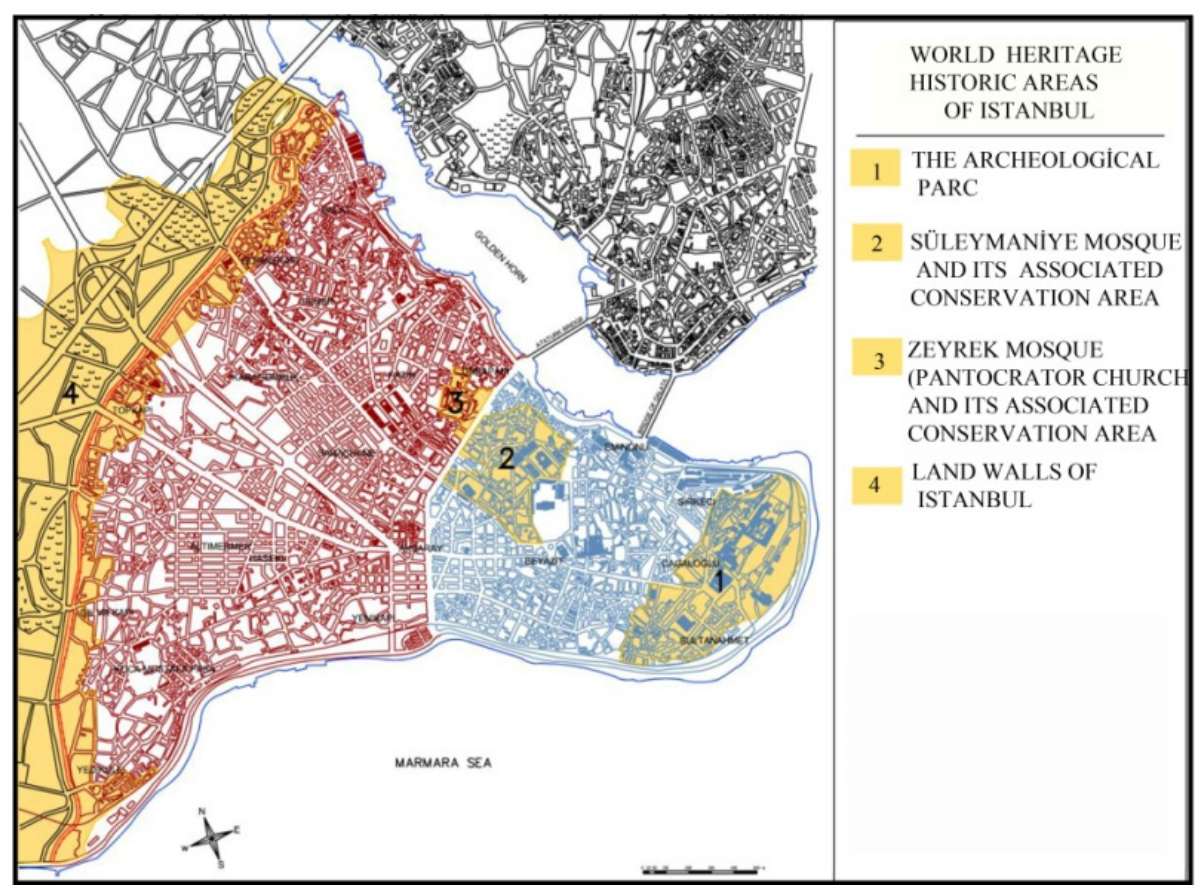

Figure 1: World Heritage areas of İstanbul. (Source:http://whc.unesco.org.)

The addition of the concept of management plan to the national conservation law in 2004 provided the start of a new protection process for Istanbul's historical sites, which are on the World Heritage List. In fact, the Istanbul Site Management Directorate was established for historical sites in 2006 and the work for management plan was initiated. In 2011, the Historical Peninsula Management Plan was approved by the Istanbul Metropolitan Municipality.

Despite the fact that conservation studies have been carried out since 1977 for the conservation of Süleymaniye settlement, the heritage site has not reach the desired level in spatial-environmental or socio-cultural and economic terms yet. This section will examine in detail the institutions responsible for the purpose, scope, content and plan preparationimplementation-auditing processes of the three recent conservation approaches to the Süleymaniye World Heritage Site and the common practices and fundamental problems in the three different conservation approaches are going to be identified.

\subsection{Revitalization projects}

Due to the increasing socio-spatial damages of historical-cultural heritage sites such as Süleymaniye and the warnings of UNESCO in 2004, in 2005, the Law No. 5366 on "Usage of Timeworn Historical and Cultural Real Property with Restoration and Protection" was promulgated. The law aims to reconstruct and restore the protected sites in accordance with the development of the region, to provide housing, trade, culture, tourism and social facilities in these regions and to protect historical and cultural immovable properties through restoring them. [10]. 93 hectares of the Süleymaniye district was declared as Revitalization Area on 24.05.2006 within the scope of this law. 


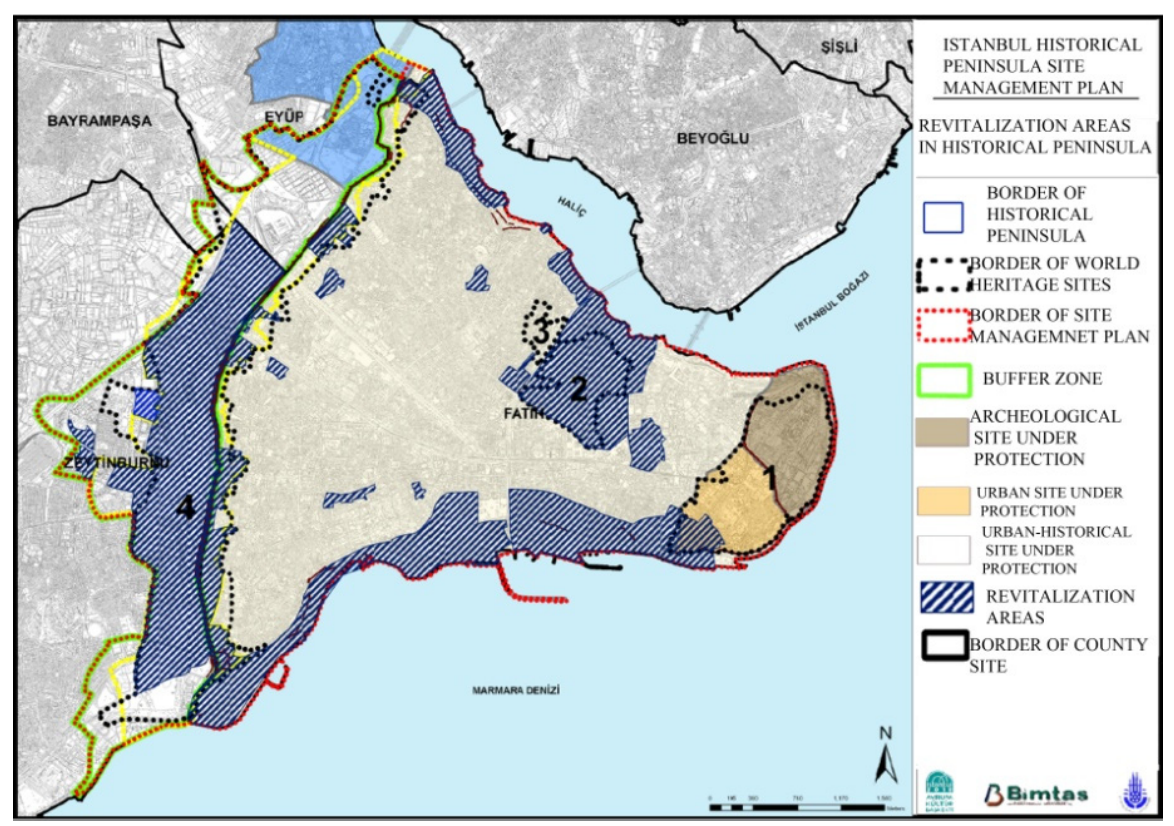

Figure 2: Revitalization areas in the historical peninsula.

The implementation process of the project which was divided into 5 stages, while 1st, 2nd and 3rd stages of the project, have monuments, registered examples of civil architecture and unregistered buildings, the 4th stage has Istanbul Drapers Market and the 5th stage has Süleymaniye Complex and Istanbul University Beyazıt Campus. In the first process, the revitalization project is aimed at the restoration of the cultural properties that are standing. The second process is projected as the reconstruction of cultural properties, which are destroyed or lost because of improper practices and about which information and documentation have been reached, in accordance with their originals. The third process aims new structures to be built on parcels without information and documentation or on parcels with unqualified structures [11]. Furthermore, functional decisions such as trade, tourism and social facilities can be taken for the region within the scope of the project.

\subsection{Conservation plan}

According to the definition of "conservation plan" in the Law no. 2863 on the Conservation of Cultural and Natural Property, it is compulsory to conduct field surveys not only of archaeological, historical, natural, architectural and demographic data of the historical sites but also of cultural and of socio-economic data. [12]. The main envisaged functions for the Süleymaniye Mosque and its Environs Protection Area in the conservation plan are the housings and public institutions such as religious facilities and training facilities. It is also foreseen that social cultural sites such as parks and recreation areas. Regions used for manufacturing and warehousing have been decided as trading area in the plan. The madrasas around Süleymaniye Mosque are defined as cultural facilities in the plan. In addition to the functional decisions, 400-700 populations/hectares density were planned in the housing areas [13]. 


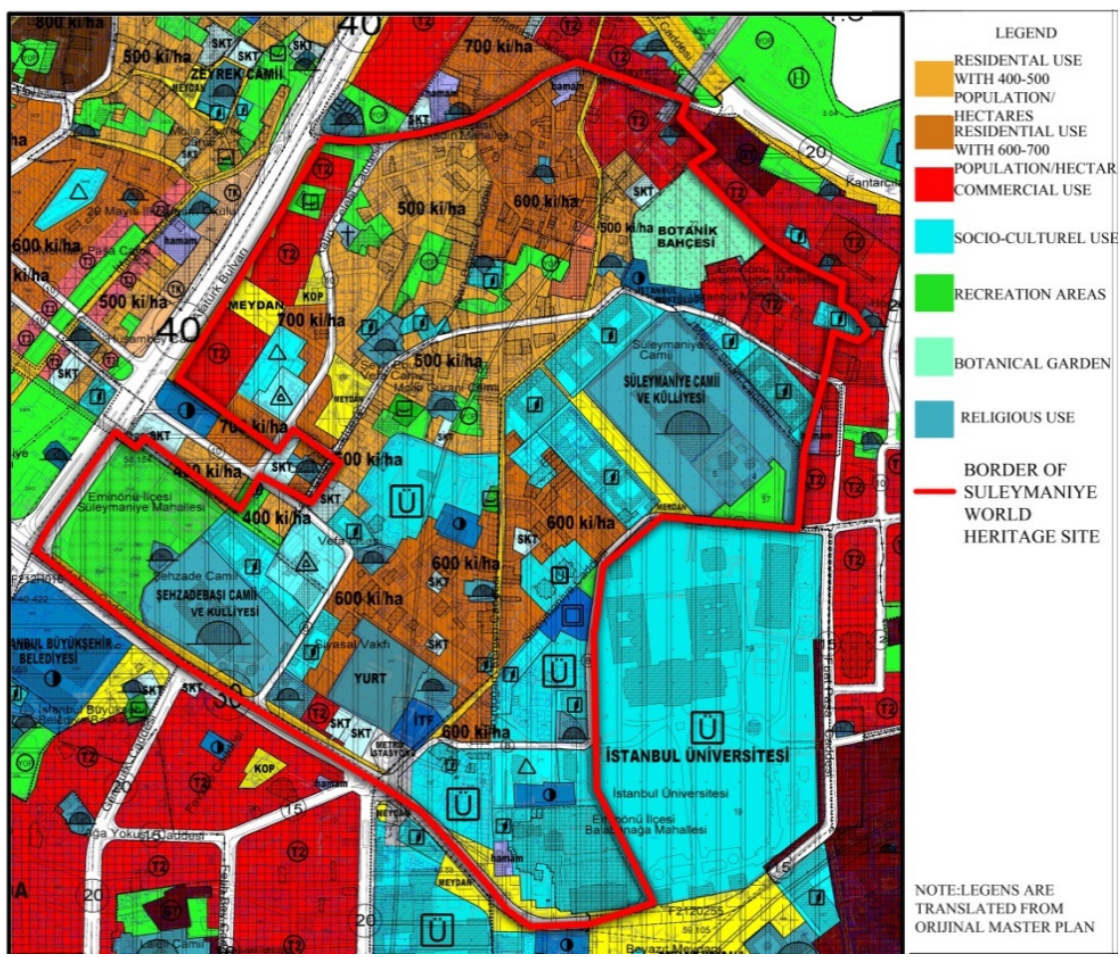

Figure 3: Plan decisions pertaining to the Süleymaniye World Heritage Site in the Fatih District Urban Conservation Site 1/5000 Scale Conservation Plan. (Source: IMM, 2010a.)

However, except functional, demographic plan decisions, there are no decisions to improve the socio-economic structure of the area and to protect the intangible cultural properties in the Historic Peninsula Conservation Plan.

\subsection{Site management plan}

When determining the Management Plan boundaries, it was found appropriate to prepare for the whole of the Istanbul Historical Peninsula considering that all of the Historical Peninsula had been a historical-urban protected area at national level since 1995, instead of preparing separate management plans for the four regions in the World Heritage List.

The problems identified regarding the settlement in Süleymaniye in this management plan are as follows:

- Inadequate conservation, decay of Monuments at Süleymaniye World Heritage Site

- Inability to protect urban architectural structures and their decay, being run-down, and in a state of collapse

- Scientific and technical errors being made in conservation and restoration implementations, not being able to achieve required quality with respect to materials and labour

- Widespread approach of demolishing and rebuilding of registered structures 
- Widespread reconstruction efforts of monuments, which do not have certificates or have been destroyed

- Financial resources created regarding conservation not being used efficiently in the effective conservation of cultural properties in the Site

- Certain sections of social complexes (Süleymaniye, Sehzadebasi) and civil architectural buildings being used for inappropriate functions

- Possible threat of loss of traditional street pattern

- Süleymaniye Mosque and surrounding World Heritage Site not being sufficiently known

Furthermore, institutions and organizations foreseen to take an active role in the implementation-monitoring and evaluation processes of the main objectives, strategies, actions and plans for these problems, which are described through spatial destruction and functional inaccuracies, are defined with general statements [14].

\section{COMPARISONS OF CONSERVATION APPROACHES \\ IN TERMS OF CONTEXT AND COORDINATION}

Integrated urban protection, also described as a contemporary conservation approach, highlighted in the 1972 World Heritage Convention and 1975 the Declaration of Amsterdam means that physical-spatial environments must be preserved along with their social, economic, administrative and occupational values [15]. This part of the study will compare the relation among the three conservation approaches being applied to the Süleymaniye

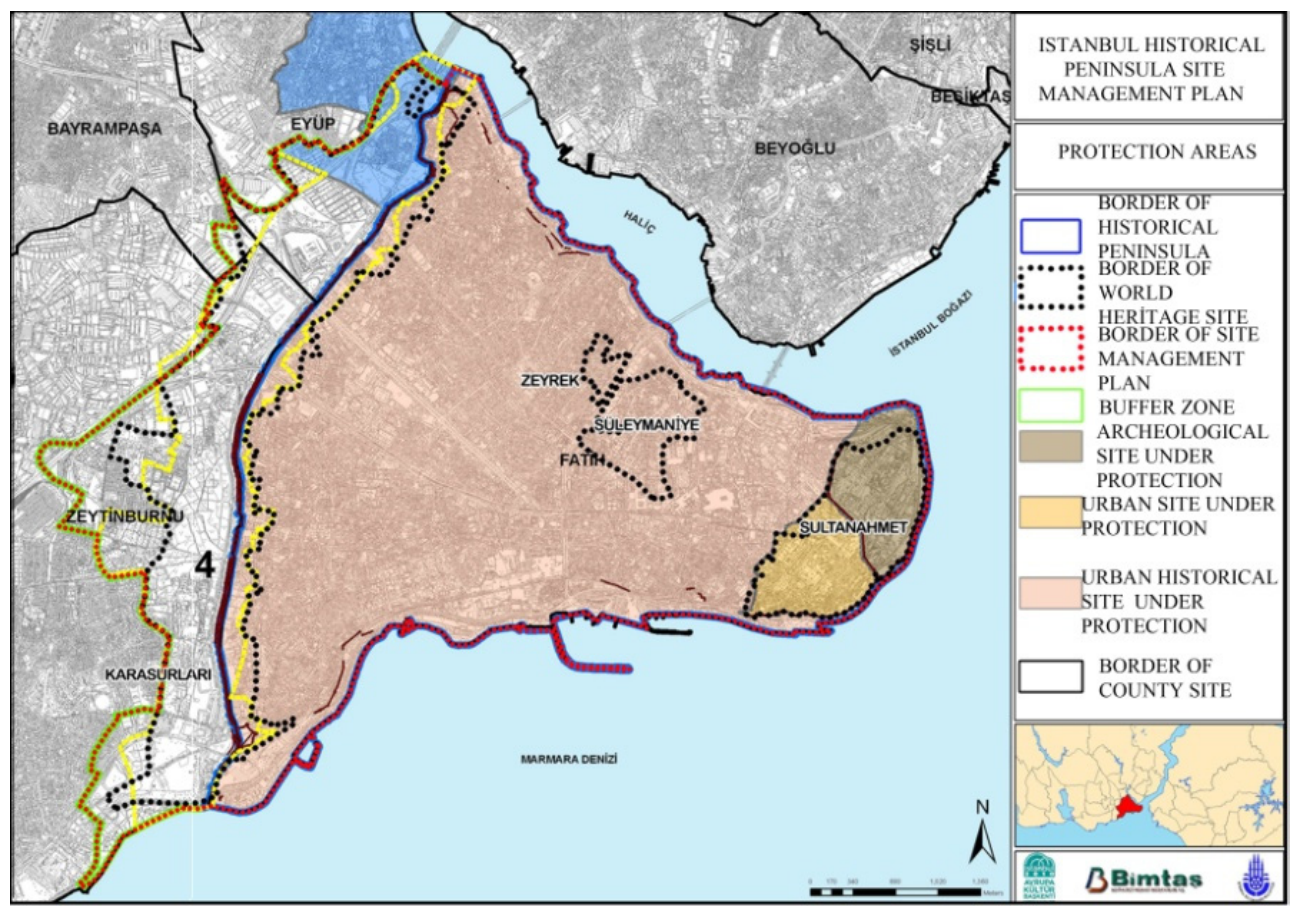

Figure 4: The borders of the site magement plan. 
Cultural Heritage in the context of objectives-targets and strategies and the scope and content of the plans will be evaluated in terms of integrated and sustainable conservation approaches by specifying the active institutions in the production-implementation-audit processes of the plan.

Firstly, revitalization projects consider the Heritage Site, as an area consisting of structures as a scope and only architectural projects has been prepared; therefore, the lack of socio-cultural and economic analyses does not contribute to the improvement of the socioeconomic structure of the region, the preservation of intangible cultural values and the maintenance of the region's soul. Considering that the physical renewal of the structures and the change of the trade structure will increase the value in the region, it seems unlikely that the region will continue to be a living space for the low-income group since it will appeal to a new mass of population. Therefore, it seems unlikely that the project will be sustainable due to the new physical, social and economic texture, it will create and it will also be a weak one in terms of integrated and versatile protection principles. It is also possible that new structures, one of the purposes of the revitalization projects can create an artificial physical environment that is foreign to the cultural heritage and it may pose a threat to the integrity and authenticity of outstanding universal values. Apart from very special cases, it is a wrong method or at least it should be discussed very seriously to set out from the stylistic features of old buildings and to determine the characteristics of the architectural elements in form, size and composition and to write them in plans and regulations for new buildings to be built in a historical environment [16]. Despite the fact that the restoration projects are based on the partnership of the private sector, the public institutions and the landlord, the restoration projects of the civil architectural structures have mostly been undertaken by private architectural offices. It can be seen that the planning and projecting processes are performed with a centralist understanding and commanding attitude, that only professionals join in decision making and the relevant parties are only given information about the results of the process and that these processes are entirely left to the initiative of the administration [17]. The fact that in the implementation process private architectural offices become the dominant actor of the project by purchasing a large part of the civil architectural structures from the owners with no economic power to restore the structure and that the municipalities also have the authority to expeditiously expropriate the civil architectural structures according to the law demonstrates that conservation principles in projects are not considered in a collaborative, transparent and broad participatory way.

The objectives set out in the conservation plan as second approach, relate only to spatial, functional and population density of the area. For this reason, multidimensional conservation approaches have been ignored and the decisions on the improvement of socio-economic structure and preservation of intangible cultural values have been insufficient. Moreover, in the case where the purposes regarding the population density are not determined in the revitalization projects, new structures have been proposed. It may be incompatible with the density decisions determined in the conservation plan and may change cultural, functional and density relations. Unclear and conflicting decisions about what should be done to protect the heritage integrity and originality in these two practices, which are carried out independently of each other to protect the cultural heritage of Süleymaniye and the uncertainty about which institution will be more effective with which actions cause concern about managing the process.

Despite the fact that there are many spatial, demographic, socio-economic and cultural problems in settlement, in the management plan, which is the latest work to protect Süleymaniye Cultural Heritage, these are not emphasized. The fact that the problems are mainly related to the spatial decay and the lack of publicity cause concern in terms of the 
intangible cultural values of Süleymaniye. The fact that there are no decisions among the objectives, target and strategies regarding the conservation and socio-economic development of the intangible cultural values of the Heritage Site makes the plan inadequate for the integrated protection of the site with sustainable methods similar to the other two protection applications. The aims have been expressed in very general statements in the plan as well as there are no specific action decisions that are described in detail on the basis of the values that make up the unique character and urban identity of the region that can create distinctiveness and awareness. The Site Management Plan contains superficial and general purposes in terms of content and implementation. The lack of mention of long-running revitalization projects in the section related to the protection of civil architecture buildings in the plan and the lack of private architectural offices in the definition of responsible institutions may also lead to confusion of authority. Furthermore, the fact that the local people are not defined as stakeholders in the protection activities and that the same institutions and organizations are regarded as responsible for carrying out all the actions shows that the requirements of the participant protection have not been understood enough.

\section{CONCLUSION}

Integrated protection problems become clearer in the case of Süleymaniye when the objectives, strategy and responsible organizations defined in the conservation-renewal and site management plan are considered according to the integrated protection criteria of the Amsterdam Declaration and the following criterias of Operational Guidelines for the Implementation;

a) A thorough shared understanding of the property by all stakeholders;

b) A cycle of planning, implementation, monitoring, evaluation and feedback;

c) The monitoring and assessment of the impacts of trends, changes, and of proposed interventions;

d) The involvement of partners and stakeholders;

e) The allocation of necessary resources;

f) capacity-building; and

g) An accountable, transparent description of how the management system functions [21].

As can be understood by UNESCO Implementation Guidelines, it is requested that all related stakeholders should act with a common understanding of protection in the state party's approach to conservation of cultural and natural heritage properties. However, the conservation approaches, we have examined, have objectives that are inconsistent with each other and are produced independently by different institutions. In addition, the social, scientific, economic and technical sustainability approaches that the Amsterdam Declaration defines under its integrated conservation criteria are lacking in all three studies. Therefore, for the settlement of Süleymaniye, there are projects, which only have an understanding of spatial revitalization and protection and do not care about the historical soul of the place.

Due to the fact that the objectives set in the site management plan are expressed with very general statements, that the two other studies are not mentioned and that the revitalization projects are implemented independently from conservation plans, it does not seem possible to achieve the "Planning-implementation-monitoring-evaluation and feedback cycle" suggested in the second criteria with these highly fragmented and independent approaches.

According to the fourth criteria, which suggests that partners and stakeholders are involved, the government must make an objective definition of relevant party, ensure equal representation of all parties, plan their participation and make all stakeholders active in protection efforts. However, 'participation and informing the public' that is expressed in the 
guidance on was not provided in the form of transparent and equal representation in renewal projects, conservation plans and finally site management plan. These plans and projects developed independently about the Historical Peninsula demonstrate that the concept and process of the 'Management Plan', which the World Heritage Committee is trying to ensure in all states, have not fully been understood.

The plans prepared without the participation of the public by the separate institutions for the protection of Süleymaniye settlements have not been successful both due to the lack of a reliable and transparent atmosphere for the implementation process and the incompatibility of the scopes and contents with the contemporary conservation understanding. In addition, the participation of actors and corporate stakeholders is a process that cannot be managed and learned in Turkey yet. The examined examples indicate that the subject is continuing over non-systematic and non-scientific applications and that there are inaccurate accumulations.

In the case of Turkey, due to legal and institutional confusions and multipartite authorities on the protection of cultural heritage sites, the contribution of the Site Management Plan has not been at the expected level. Despite these three conservation approaches for the Süleymaniye settlement, spatial and social decay has been continuing to increase over time. The main cause for this is that protection work is prepared with a multipartite perspective, without taking integrity into account, and more importantly far from the principles of integrated protection and participation. All the three examined examples demonstrate that the institutions that take part in conservation work, focusing on Turkey's natural and cultural heritage must first develop a common and integrated conservation language, conduct a good stakeholder analysis and have comprehensive and holistic conservation legislation. Cultural heritage is a whole, not only with the superior single structures but with the people, their cultural values and social lives and it should be protected thus. Historical urban centres should be considered together with the social and economic problems of the inhabitants of the region as much as possible and should be designed with intangible cultural values. Moreover, the protection of the cultural heritage should not be a matter of only experts, institutions and organizations, society should give conscious support to conservation work. People must effectively take a part in every stage of the work, from planning to its implementation and control, in a participatory, transparent and collaborative atmosphere. If we cannot integrate concrete architectural items with the community and cannot deal with them, protection will never be fully ensured.

\section{REFERENCES}

[1] UNESCO, Convention Concerning the Protection of the World Cultural and Natural Heritage, Paris, 1972.

[2] WHC, Operational Guidelines for the Implementation of the World Heritage Convention, Paris, 2016

[3] The Law No. 2863 on the Conservation of Cultural and Natural Property, T.R. Official Journal, 1983.

[4] Strutz, J.,Re-inventing the past for a new Istanbul: The urban transformation project in Süleymaniye. Journal of Society and Science. 124. p. 126, 2012.

[5] Balcan, C., Urban Renewal and The Story of Two Cities: Tarlabası Süleymanıye, Published master's thesis, Mimar Sinan Fine Arts University, p. 115, 2012.

[6] IMM.,The Historic Peninsula Site Management Plan, İstanbul.2011.

[7] Balcan, C., Urban Renewal and The Story of Two Cities: Tarlabası Süleymanıye, Unublished master's thesis, Mimar Sinan Fine Arts University, pp. 125-127, 2012. 
[8] Şen, B., Urban Regeneration in the Historical City Center of İstanbul: An inside Look at Spatial Intervention or Considering Spatial with Social Journal of Society and Democracy.11 (Jan.-Jun.), pp. 37-38, 2011.

[9] The Law No. 5366 on Usage of Timeworn Historical and Cultural Real Property with Restoration and Protection, T.R Official Journal, 2005.

[10] The Law No. 5366 on Usage of Timeworn Historical and Cultural Real Property with Restoration and Protection., T.R Official Journal (Definitions), p. 12005.

[11] Dinçer, İ., Discussing Urban Conservation and Renovation Problems with Examples: Süleymaniye and Tarlabaşı. Planlama.org. p. 3. Online http://www.planlama.org/ index.php/duyurular/66-planlamaorg-yazlar/doc-dr-clal-dincer/325-kentsel-korumave-yenileme-sorunlarn-oernekler-uezerinden-tartmak-sueleymaniye-ve-tarlaba-4. Accessed on: 10 Aug. 2017

[12] The Law No. 2863 on the Conservation of Cultural and Natural Property. T.R. Official Journal (Definition), p. 1, 1983.

[13] 30.12.2011 Approval Date Historical Peninsula with Historical Urban Archaeological Site, 1st Degree Archaeological Site 1/5000 Scale Protected Master Plan Report.

[14] IMM., The Historic Peninsula Site Management Plan, İstanbul, pp. 193-198. 2011.

[15] Congress on the European Architectural Heritage., The Declaration of Amsterdam, 1975.

[16] Eldem, N., History-Conscious and Contemporary Personality. Arredamento Dekoracion, May, pp. 100-101, 1992.

[17] Dinçer,İ. ,Discussing Urban Conservation and Renovation Problems with Examples: Süleymaniye and Tarlabaşı. Planlama. Org, p. 2, Accessed on: 10 Aug. 2017. 